\title{
Novel insights on GM1 and Parkinson's disease: A critical review
}

\author{
Maria Fazzari ${ }^{1}$ - Erika Di Biase ${ }^{1}$. Giulia Lunghi ${ }^{1}$. Laura Mauri ${ }^{1}$ - Elena Chiricozzi ${ }^{1}$ Sandro Sonnino ${ }^{1}$ (I)
}

Received: 12 May 2021 / Revised: 2 August 2021 / Accepted: 24 August 2021 / Published online: 22 January 2022

(c) The Author(s) 2021

\begin{abstract}
GM1 is a crucial component of neuronal membrane residing both in the soma and nerve terminals. As reported in Parkinson's disease patients, the reduction of GM1 determines the failure of fundamental functional processes leading to cumulative cell distress up to neuron death. This review reports on the role of GM1 in the pathogenesis of the disease, illustrating the current data available but also hypotheses on the additional mechanisms in which GM1 could be involved and which require further study. In the manuscript we discuss these points trying to explain the role of diminished content of brain GM1, particularly in the nigro-striatal system, in Parkinson's disease etiology and progression.
\end{abstract}

Keywords GM1 ganglioside $\cdot$ GM1 oligosaccharide $\cdot$ Parkinson's disease $\cdot$ Neuronale receptors

\section{GM1 ganglioside}

The ganglioside GM1 (Fig. 1) is an amphiphilic compound displaying a carbohydrate head group with hydrophilicity well balanced by the hydrophobicity of the lipid moiety, the ceramide, inserted into the outer layer of the membrane. Due to intra-residual interactions between the sialic acid lateral chain and the $N$-acetylgalactosamine, the trisaccharide $\beta$-GalNAc-(1-4)-[ $\alpha$-Neu5Ac-(2-3)]- $\beta$-Gal of GM1 oligosaccharide acts as a single rigid unit conferring a limited dynamic to the moiety $[1,2]$. Some mobility is associated to the $\beta$-Gal-(1-3)- $\beta$-GalNAc- terminal linkage that is available in two couple of torsional angles, this allowing multiple conformers and several interactions with the other membrane components or extracellular ligands [3].

GM1 belongs to the "a" series gangliosides and its biosynthesis occurs in the Golgi apparatus [4]. In addition, a portion of membrane GM1 can be synthesized from complex gangliosides, particularly from GD1a, by the membrane bound sialidase Neu3 that works also in a trans fashion on substrates belonging to neighboring cells $[5,6]$.

Maria Fazzari and Erika Di Biase contributed equally to this work

Sandro Sonnino

sandro.sonnino@unimi.it

1 Department of Medical Biotechnology and Translational Medicine, University of Milan, Milan, Italy
GM1 is a component of the neuronal membranes [7], being particularly abundant in the central nervous system, where it covers $10-15 \%$ of the total ganglioside content (about $0.9 \mathrm{mg}$ sialic acid lipid bound/g of fresh brain) [8, 9]. GM1 and the more complex gangliosides are enriched in the pre- and postsynaptic membranes of the synaptic terminals $[10,11]$. A minor quantity of GM1 is available on the surface of neuronal body. In addition, at lower concentration GM1 can also be found in the non-nervous system tissues [3].

As the other gangliosides, a small amount is present in the cell cytosol complexed with proteins and corresponds to about $3 \%$ of the total [12]. We recall that monomers of GM1 are available is solution only at very low concentration not over $10^{-9} \mathrm{M}$. Over this concentration, GM1 monomers aggregate forming quite spherical micelles, suggesting that stable complexes of monomers with proteins are rapidly formed [13-15].

The peculiarity of the ganglioside structure allows to establish multiple interactions involving: $i$ ) the hydroxyl groups of the carbohydrate portion that can make hydrogen bonds with other neighboring molecules, $i i)$ the amide and hydroxyl groups of the ceramide inserted into the membrane that act as both donors and acceptors of hydrogen bonds and allow lateral interaction with other lipid molecules [16, 17]. These physico-chemical properties of gangliosides provide the driving force for lateral membrane segregation and the formation of rigid floating domains enriched in 
Fig. 1 Structure of ganglioside GM1, II3Neu5AcGg4Cer and of its LIGA20 analogue. LIGA20 has a greater ability to cross BBB than GM1 and showed superior neuroprotective efficacy in PD animal models
GM1

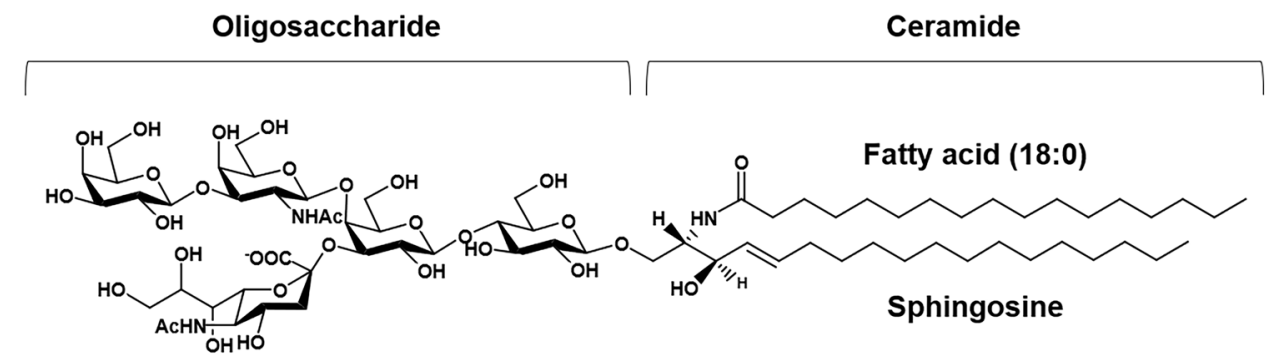

LIGA20

Oligosaccharide

Ceramide

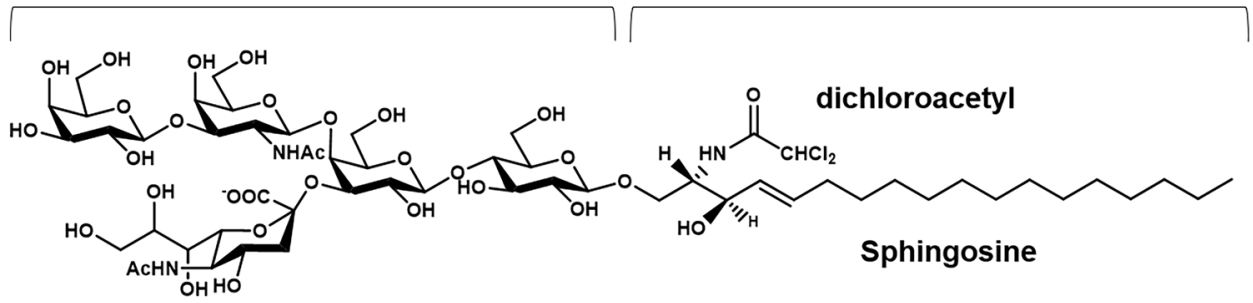

sphingolipids, cholesterol and palmitoylphosphatidylcholine, named lipid rafts [16, 17].

The ability of the cholera toxin to recognize and selectively bind GM1 is used as a common experimental method for the identification of lipid rafts in cells and tissues [18-20].

Among all gangliosides, GM1 is surely that most studied for its bioactive potential. Starting from the beginning of the'80, Scientists rapidly developed studies on GM1, attracted by its neurotrophic and neuroprotective properties $[2,3,21]$. This was facilitated by the large availability of gangliosides that occurred when drugs named Cronassial (containing bovine brain ganglioside mixture) and Sygen (containing highly purified GM1) were brought to market in 1973 and 1985, respectively, for therapy of peripheral neuropathies [22, 23]. In those years, several clinical trials of different extension, comprising from a few to thousands of patients affected by neurodegenerative diseases, cerebral and spinal injuries were also carried out [24-33].

In the context of Parkinson's disease (PD), the neuroprotective potential of GM1 emerged since the late 1980s studies on mouse and primate disease models exposed to 1-methyl-4-phenyl-1,2,3,6-tetrahydropyridine (MPTP), a neurotoxin that affects the dopaminergic system causing a bioenergetic deficit [34-39]. More recently, the GM1 therapeutic potential has also been confirmed in rats overexpressing the human A53T mutant $\alpha$-synuclein $(\alpha S)$ via adenoassociated viral vector [40].

The promising preclinical studies supported the development of clinical trials where GM1 replacement therapy demonstrated a modest but significant efficacy improving motor and cognitive outcomes of treated PD patients [41-43]. However, the results lacked strong statistical power to obtain FDA approval as a drug for treating PD, probably due to the small cohort of patients enrolled in these trials [41-43]. Additionally, the GM1 limited bioavailability and blood brain barrier penetrance when systemically administered further hampered its clinical development. In this context, the recent discovery that the oligosaccharide of GM1 represents the bioactive portion provides a new promising drug candidate for PD patients. Thanks to its capability of easily crossing the blood brain barrier, the GM1 oligosaccharide alone is able to perfectly replicate the neurotrophic and neuroprotective properties of the entire GM1 both in vitro and in vivo [44-51].

\section{Biosynthesis of GM1 and PD}

GM1 is the final product of the glycosyltransferase-dependent sequential synthetic process CerGlcCerLacCerGM3GM2GM1, following the scheme reported in Fig. 2. The reduction or the lack of expression of any glycosyltransferase involved in each step limits the availability of GM1 as well as of any following complex ganglioside.

During neuronal differentiation, maturation and synaptogenesis, sialic acid containing glycosphingolipids undergo dramatic changes with the shift from simple gangliosides (GM3, GD3) to complex ones (GM1, GD1a, GD1b and GT1b) [49]. A detailed analysis of ganglioside 
content in human brains from subjects of different ages revealed that during aging a physiological reduction of GM1 and GD1a occurs and that their content varies significantly among individuals of the same age [52]. Starting from this observation, it was proposed that, in individuals owning a level of a-series gangliosides at the limit of the normal range, the decrease of GM1 and GD1 a below the critical threshold value necessary for maintaining crucial neuronal functions [21] can trigger neuropathological dysfunctions leading finally to PD onset [2, 53]. Accordingly, PD patients display a decreased expression of B4galnt1, B3galt4 and St3gal2 genes, key players for the synthesis of GM1 and more complex gangliosides belonging to b-series [53,54]. As a consequence, the levels of complex gangliosides, including GM1, GD1a, GD1b and GT1b, are reduced in the substantia nigra (SN) [55], in the occipital cortex [56] and in peripheral tissues of PD patients [53]. The aberrant ganglioside synthesis and the consequent depletion of complex gangliosides, especially of a-series, implies an altered membrane composition leading to the vulnerability of dopaminergic neurons. In this view, the dysfunction of ganglioside synthesis can be considered as a causative event underlying the onset of $\mathrm{PD}$, suggesting that a systemic GM1 depletion may be a risk factor in PD.

The direct association between GM1 depletion and Parkinsonian degeneration clearly emerged in the mouse model carrying a loss of function deletion in B4galnt1 gene [57]. This gene codifies for $\mathrm{b}-1,4-\mathrm{N}$-acetylgalactosaminyltransferase 1 , the enzyme catalyzing the transfer of $\mathrm{N}$-acetylgalactosamine onto GM3 and GD3 that gives rise to GM2 and GD2 which in turn are metabolized to GM1 and GD1b [58]. Specifically, $\mathrm{Wu}$ and coworkers demonstrated that the disruption of B4galnt1 gene in mice determines the development of typical PD features both in central and in peripheral tissues: motor impairment, loss of dopaminergic neurons from $\mathrm{SN}, \alpha \mathrm{S}$ aggregation, alterations of gastrointestinal, sympathetic cardiac, and cerebral cognitive systems $[56,57,59,60]$. Of interest, the heterozygous disruption of the B4galnt1 gene causing a partial depletion of GM1 comparable to those found in PD patients showed a late-onset but indistinguishable pattern of neurodegeneration if compared to homozygous mice [56, 59]. Remarkably, the administration of exogenous GM1 to B4galnt1-defective mice was able to recover both motor and non-motor PD symptomatology, suggesting that GM1 enters the brain even though in limited amounts. In accordance, the treatment resulted more therapeutically effective when mice were injected with a GM1 membrane-permeable analogue (LIGA20) containing the dichloroacetyl group instead of the stearic acid (Fig. 1) [59]. Similarly, the administration of GM1 oligosaccharide portion, owning a high capability to cross blood brain barrier [50], fully recovered both biochemical and behavioral Parkinsonian symptoms of $B 4$ galnt $1^{ \pm}$mice [47].

\section{The GM1-protein interactions}

It has been almost 50 years since it was reported that gangliosides interact with proteins and that this is necessary for regulating their activities during physiological processes. Interactions are largely due to the capability of their carbohydrates to form hydrogen bonds, but, in some cases, they are driven by the membrane organization resulting from lipid moiety around the protein and by the hydrophobic forces. The role of GM3 [61], GM1 [45, 62], GD1b [63, 64], GT1b [65] and GQ1b [66] in regulating, positively or negatively, protein processes has been studied in detail. On the other hand, it is necessary to recall that also many neutral glycosphingolipids, with their oligosaccharide chains, interact with microorganism proteins and this is instrumental for bacteria and virus to invade our cells $[67,68]$.

The first information on the GM1-protein interactions dates back, probably, to the discovery that GM1 is the receptor for the cholera toxin [18-20] and it is involved in recruiting the toxin into the cells. In the following years, the interaction of GM1 with the serum proteins has been studied in detail $[69,70]$. GM1 micelles incorporate serum albumin in a ratio of 1:1 (1 micelle: 1 protein). The complex slowly and irreversibly forms a big dimeric aggregate. The interaction between GM1 micelles and albumin is mostly hydrophobic. At GM1 submicellar concentrations (lower than $10^{-9} \mathrm{M}$ ) the binding of ganglioside monomers to albumin also occurs [70]. This process is due, however, to a non-specific, reversible adhesion of GM1 molecules on the albumin surface with no apparent perturbation of the albumin structure.

The importance of GM1 molecule lies in the fact that besides playing a structural role for the formation and maintenance of lipid rafts, it also has a bioactive role. On the cell membrane, GM1 contacts both sensing molecules such as growth factors and neurotrophins and their respective receptors, actively participating in the modulation of transmembrane signaling $[2,21]$. In the neurodegenerative and PD context, two main signalings have been reported to be particularly influenced by GM1: the NGFTrkA and the GDNF-GFRa1-Ret axes. Both signalings support neuronal survival, metabolic activity, plasticity and neuronal transmission (Fig. 3). In the next paragraphs we will deepen the way in which GM1 intervenes in these axes.

Furthermore, the pathognomonic sign of PD is the presence of fibrils and accumulation of the $\alpha \mathrm{S}$ protein. Although its function is still unclear today, the relationship between the protein and GM1 has recently been reported [53]. In the section below we will further explore the pathophysiological implications of this relationship. 


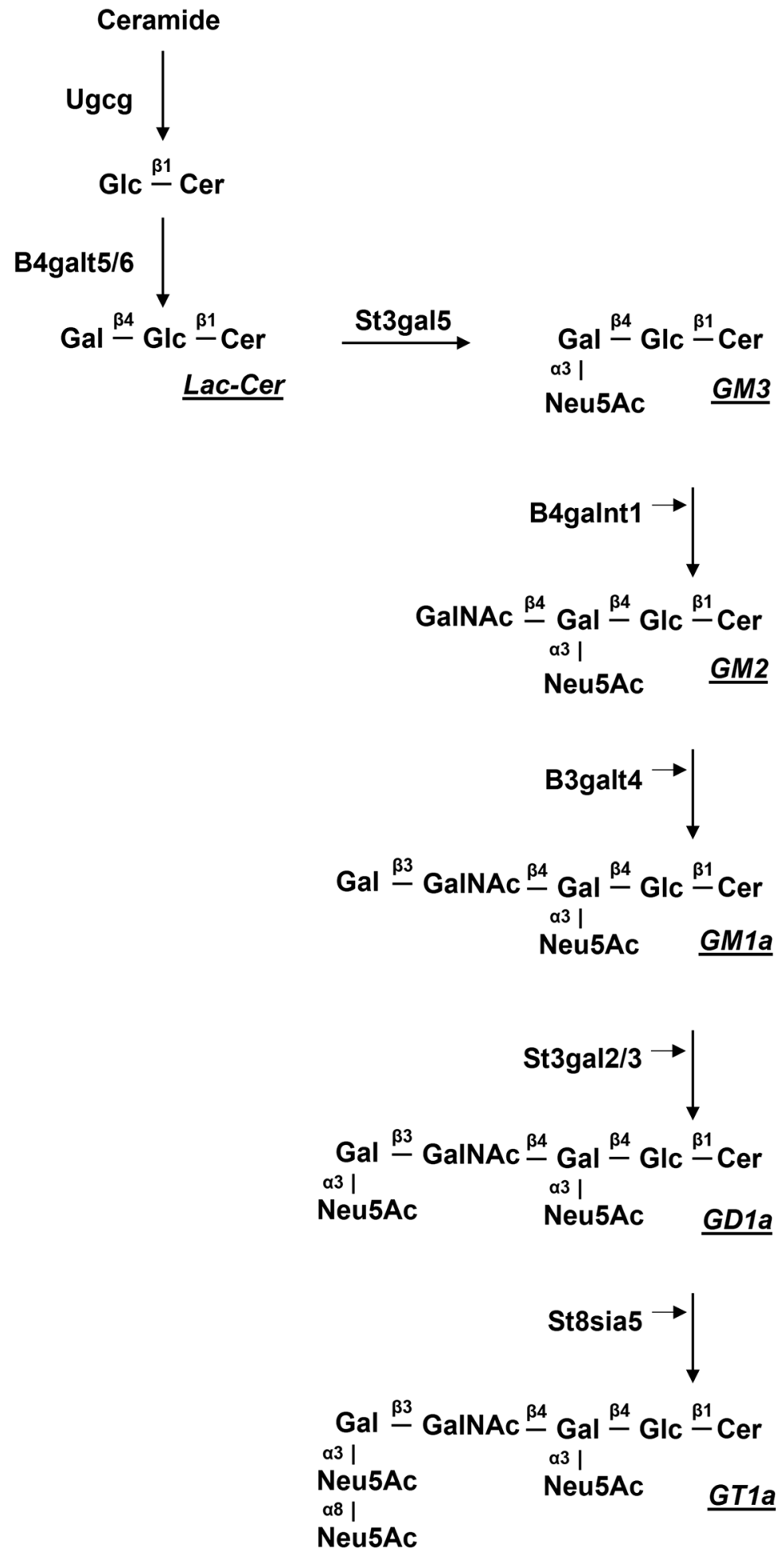


४Fig. 2 Scheme of a-series and b-series gangliosides biosynthetic pathway. A- and b-series are classified according to the number of sialic acid residues attached to lactosylceramide (Lac-Cer), respectively 1 and 2 residues. The precursor of a series of gangliosides is GM3, directly synthesized from Lac-Cer by the action of the enzyme GM3 synthase (St3gal5). GM3 is converted to GD3 via GD3 synthase (St8sia1) serving as a precursor for the $b$ series. The elongation of the precursors is performed by the sequential action of the following enzymes: GM2/GD2 synthase (B4galnt1), GM1a/GD1b synthase (B3galt4), GD1a/GT1b synthase (St3gal2/3), GT1a/GQ1b synthase (St8sia5). Cer, ceramide

\section{The TrkA-GM1 receptor}

Neurotrophic factors are key molecules for neuronal differentiation as well as survival of mature neurons. Among them, nerve growth factor (NGF) specifically binds the TrkA receptor at plasma membrane which activation requires the interaction with GM1 oligosaccharide in the extracellular space, thus functioning as a three-component complex TrkA-NGF-GM1 (Fig. 4) [44, 45, 62, 71, 72].

In the presence of NGF, neuroblastoma Neuro2a and pheochromocytoma PC12 cells slowly differentiate in culture, whereas, as expected, the main process occurring is their replication.

Although these cells express the TrkA receptor, they have a low GM1 content and do not synthetize NGF, that can however be provided by the cell culture medium $[44,62]$. Interestingly, the addition of exogenous GM1 to cells growth in NGF-containing culture medium arrests the cell replication and rapidly activates the cell differentiation with the formation of neurites $[44,62,72]$. This process is mediated by the activation via autophosphorylation of membrane TrkA receptor triggering the ERK1/2 downstream pathway activation [44, 62, 72]. By administering GM1 oligosaccharide to Neuro2a cells, the potentiation of TrkA phosphorylation is followed by PLC $\gamma$ and PKC activation with the opening of calcium channels on the plasma membrane and on intracellular storages [51]. Additionally, the GM1 oligosaccharideinduced neurite sprouting was abolished by administration of calcium chelators meaning that the calcium increase is crucial for this neurodifferentiative process [51].

Several detailed studies showed that the GM1 added to cell culture medium becomes a component of the plasma membrane in a time and concentration dependent manner, increasing the original GM1 content of the cell [73-76]. In all studied cell models, a portion of the exogenously administered GM1 is taken up by the cells and associates with the plasma membrane lipid rafts, apparently indistinguishable from the endogenous GM1, thus entering in the basal cell ganglioside metabolic process [73-76]. Repression of the cell synthesis of GM1 by molecular biology procedures in presence of NGF do not induce the differentiation process, suggesting that NGF is not capable of activating the TrkA receptor in the absence of GM1 or at low GM1 cell content [77].

The first study assessing the GM1 direct interaction with TrkA was performed using the low GM1 expressingPC12 cells [62]. The GM1 administered to the cells could be immuno-precipitated with an anti-TrkA antibody as TrkA-GM1 complex. The complex was separated by polyacrylamide gel electrophoresis (PAGE) and the presence of GM1 identified by cholera toxin [62]. In Neuro2a cells the interaction between TrkA and GM1 was studied by using a photoactivable and tritium-labeled GM1 ganglioside. The administration of this GM1 derivative to cells, followed by illumination, lead to the formation of a complex of covalently linked GM1 and TrkA. The complex being radioactive could be identified by radioimaging after PAGE separation. The use of a GM1 containing the photoactivable group at the end of ceramide moiety or at the external galactose, and of the GM1 oligosaccharide containing the photoactivable group at the $\mathrm{C} 1$ of the glucose residue allowed to establish that the interaction of GM1 with the TrkA involves the GM1 oligosaccharide and not the GM1 ceramide [45]. This means that the ceramide of GM1 is not that close to the intramembrane portion of TrkA, while the distance between the oligosaccharide and the extracellular portion of TrkA is short enough to allow the chemical reaction between the two molecules after UV illumination [45].

The GM1-TrkA-NGF complex was studied in detail by molecular docking analyses since the crystallographic structure of the extracellular segment of human TrkA in complex with NGF is currently available and the conformation of the GM1 oligosaccharide as well. This allowed to establish that the addition of GM1 to the TrkA-NGF complex leads to a very stable tri-component complex showing a gain of stability corresponding to about $-7 \mathrm{kcal} / \mathrm{mol}$ [44].

Comparable results describing the GM1 role on the activity of the TrkA receptor were obtained using mouse primary neurons [78]. At the first $h$ in culture, these cells have very low sialic acid-bound lipids and hardly detectable GM1 [79]. The synthesis of gangliosides proceeds exponentially with the days in culture, parallel to the increase of expression of specific ganglioside glycosyltransferases [79]. The content of gangliosides reaches a plateau in 6 days of culture following the physiological neuronal maturation process. Interestingly, the artificial increase of endogenous GM1 content by administering the ganglioside to the cells during plating determined the acceleration of the neuronal maturation, as indicated by the faster formation of neuronal clusters as well as by the more complex neuronal network with respect to controls [80]. Similarly, the administration of GM1 oligosaccharide to the NGF-expressing cerebellar granule neurons led to enhanced neuronal clustering, arborization and networking together with increased levels of phosphorylation FAK and Src proteins known to be key regulators of 


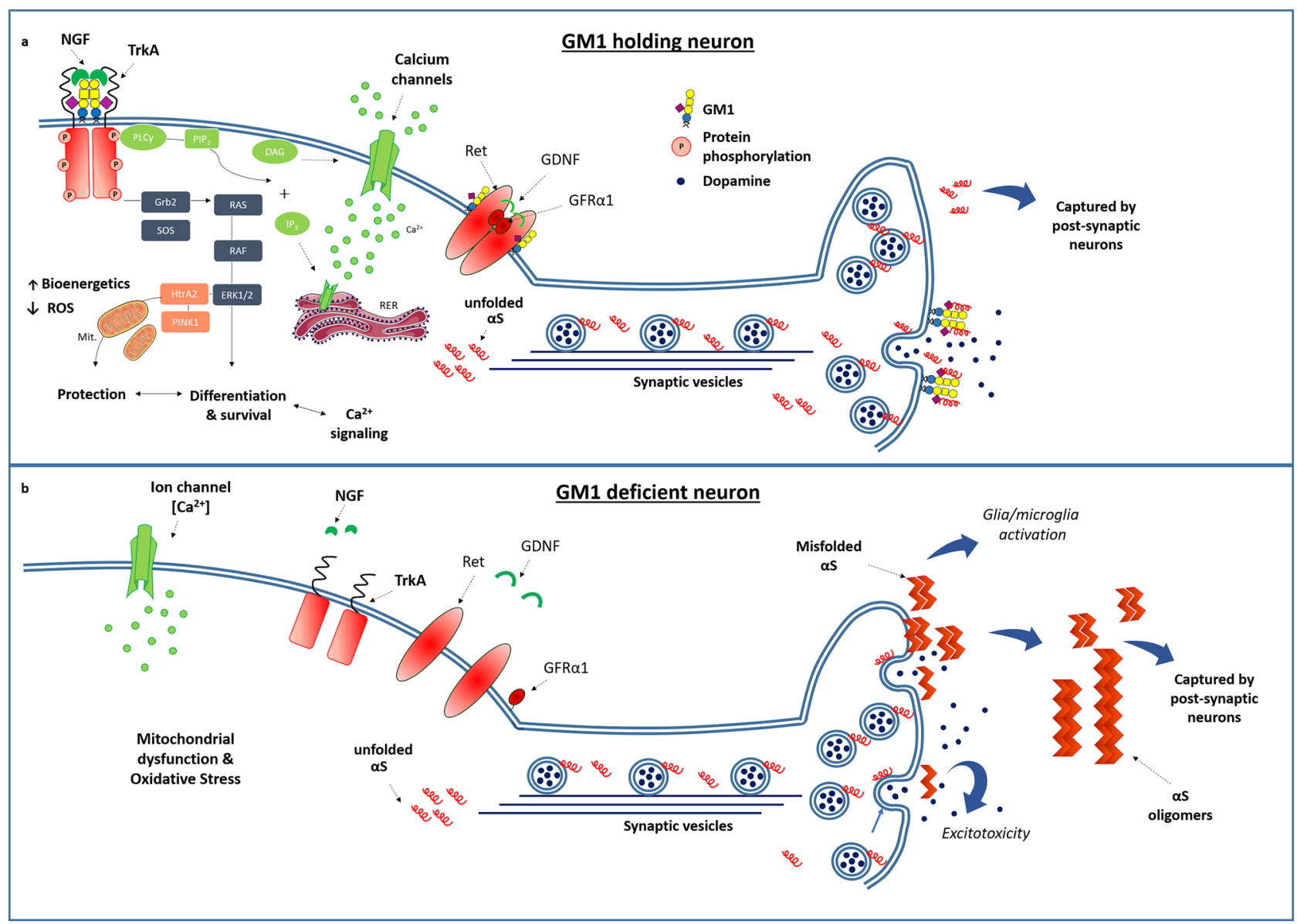

Fig. 3 Schematic representation of some neuronal processes requiring GM1. a On the top of the image is represented a healthy neuron with normal GM1 levels sustaining the fundamental neuronal signalings and the correct $\alpha$-synuclein $(\alpha S)$ folding. In particular, GM1 interacts with neurotrophins' receptors and ion channels mediating neurotrophic and neuroprotective signalings. GM1 is represented also interacting with $\alpha \mathrm{S}$, preventing its pathogenic aggregation. b On the

neuronal motility [49]. Additionally, GM1 oligosaccharide induced an increased expression of complex ganglioside and specific neuronal markers, suggesting an improved maturation respect to controls [49]. At molecular level, this process was accompanied by the activation of TrkA at cell surface and the following MAPK signaling cascade [49].

All these results lead to the conclusion that NGF is the switch that allow the TrkA signaling cascade but that without GM1 this molecular event cannot proceed. A specific TrkA-GM1 ratio seems to be required, but this probably does not correspond to the 1:1 molar ratio inside the membranes, being the TrkA amount much lower than GM1 even when the GM1 content is very low. This latter point deserves some considerations. GM1 is mainly a component of membrane lipid rafts but TrkA does not belong to these domains in PC12 and Neuro2a cells [45, 81]. The addition of NGF to PC12 cells is sufficient to translocate bottom, a neuron with GM1 deficiency showing the loss of all the important neurotrophic signals and $\alpha \mathrm{S}$ aggregation and accumulation outside the synapsis. In this aggregated form the $\alpha \mathrm{S}$ moves towards post-synaptic and other cells causing neuronal distress and the activation of the inflammatory/immune response. Modified from Chiricozzi et al. [105]

it into lipid rafts [81], whereas the activation of TrkA by GM1 treatment in Neuro2a cells is not accompanied by the translocation of the receptor into rafts domains [45]. The data available on the crystal structure of the extracellular portion of TrkA suggests that this portion has enough flexibility to lie down on the cell surface finding the GM1 oligosaccharide, this occurring when the GM1contaning lipid raft is not too far from the TrkA present in its environment. Of course, we cannot exclude that the GM1 interacting with TrkA belongs to that quantity external to the lipid rafts representing the $30-35 \%$ of GM1 [3, 82]. In neuronal primary cells, the process seems to be more unclear due to their specific morphology. Indeed, the majority of GM1 is associated to the membranes of nerve endings, while only a minor quantity of the ganglioside, residing inside or outside the lipid rafts, can be found in the neuronal body where TrkA receptor is enriched [3, 82]. 
Fig. 4 Representation of GM1 interaction with TrkA and Ret receptors at the plasma membrane level. GM1 interacts with TrkA, stabilizing the TrkA-NGF complex, allowing the TrkA autophosphorylation and activation. Adequate levels of GM1 are also necessary to maintain the Ret signaling, stabilizing the tripartite complex GDNFGFR $\alpha$-Ret

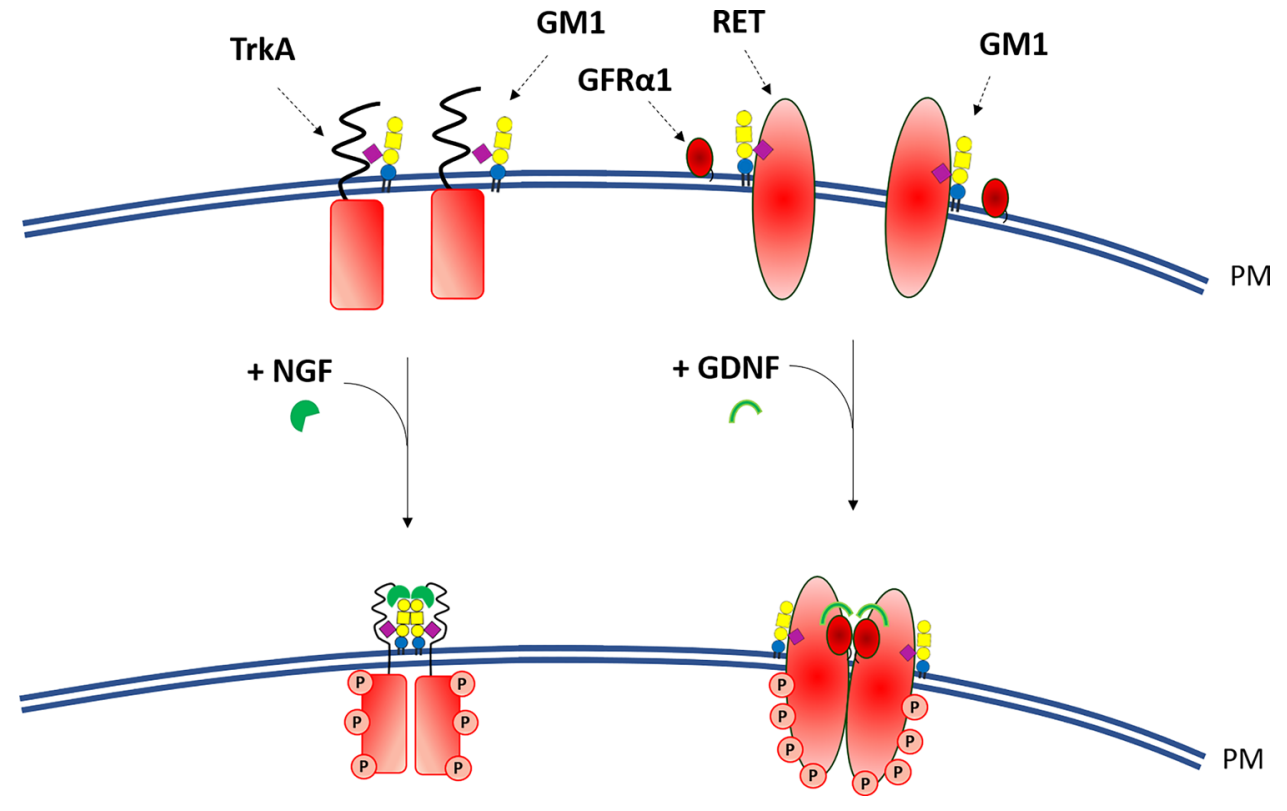

In conclusion, the information available supports that GM1 is necessary for the activity of TrkA and that NGF can modulate TrkA function only in presence of a correct amount of GM1 on the cell surface and by interacting with it. This sustains the idea that the true receptor for NGF is the complex TrkA-GM1. However, additional studies are necessary to correctly understand how these membrane events occur. Is the TrkA-GM1 complex firstly available to bind NGF, which then acts to dimerize the TrkA-GM1 complex? Or does the NGF first facilitate TrkA dimerization forming the double-dimer TrkA-NGF-NGF-TrkA complex which is then stabilized by binding to GM1?

\section{The Ret-GM1-GFRa1 receptor}

Ret is a transmembrane receptor with tyrosine kinase activity that, upon dimerization and autophosphorylation, activates the intracellular signaling regulating a myriad of cellular functions: cell survival, differentiation, proliferation, migration, chemotaxis, ureteric bud branching, neurite outgrowth and synaptic plasticity [83]. These Ret functions are regulated by the interaction with the GDNF family ligands (GFLs) to which various neurotrophic factors belong. However, the binding affinity between Ret and GFLs is extremely low and would not occur per se. In fact, the intervention of other molecules, named GDNF-family receptors alpha $(\mathrm{GFR} \alpha)$ is required, which act as co-receptors stabilizing the tripartite complex GFL-GFR $\alpha$-Ret. GFR $\alpha$ s are GPIanchored proteins of which 4 members are known (GFR $\alpha 1$ 4), each specific to a single GFL.

GDNF is a homodimeric protein [84] indispensable for the maintenance and survival of dopaminergic neurons [85]. GDNF is recognized by GFR $\alpha 1$ and their binding allows Ret association in a multiprotein complex with a $\mathrm{GDNF}_{1}(\mathrm{GFR} \alpha 1)_{2}(\mathrm{Ret})_{2}$ stoichiometry [86] recently confirmed by Cryo-EM [87]. GFR $\alpha 1$ localizes to the lipid rafts and upon interaction with GDNF it associates with GM1, thus recruiting Ret to the rafts domains and promoting its autophosphorylation (Fig. 4) [88, 89]. Only in this way an adequate activation of the raft-associated downstream signaling molecules such as Src kinase is achieved [88]. A major failure of GDNF signaling occurs in PD $[56,58,90]$ and seems to be a promising therapeutic target for neuroprotective and regenerative interventions in PD patients [90]. Indeed, PD patients present reduced levels of GDNF and phosphorylated Ret within the SN and striatum [56, 85]. As stated above, suboptimal levels of GM1 have also been reported in the SN of PD patients [59] with a linear correlation between the levels of GM1 and the degree of Ret phosphorylation in the $\mathrm{SN}$ dopaminergic neurons of $\mathrm{PD}$ patients [56]. In this regard, the importance of GM1 is evident from the $B 4$ galnt $I^{ \pm}$mouse model, deficient for all gangliosides including GM1. This mouse strain develops parkinsonism in old age with a strong deficit of GDNF signaling which is rescued following the administration of the GM1 analog, LIGA20 [56, 59]. In fact, LIGA20 infusion restores the adequate level of Ret phosphorylation and the downstream transducers (Src and MAPK), allowing a recovery of both the molecular signaling and phenotypic pathological features. Adequate levels of GM1 are therefore necessary to maintain GDNF / Ret signaling, despite its minority percentage in neuronal lipid rafts when compared with GD1a, GD1b and GT1b. However, none of the latter gangliosides except GM1 is co-immunoprecipitated with phosphorylated Ret and GFR $\alpha 1$ in the SN of wt and B4galnt ${ }^{ \pm}$mice. Which are the sites of interaction between GDNF-GFRa1-Ret and 
GM1 and which is the role played by the specific sequence of the GM1-oligosaccharide are still open questions to date.

\section{a-Synuclein and GM1—protein interactions}

Pathognomonic sign of PD is the presence of fibrils accumulation of the $\alpha \mathrm{S}$ protein, which forms intracellular and intercellular inclusions known as "Lewy bodies" by capturing inside dozens of other proteins and lipidic species [91]. $\alpha \mathrm{S}$ is a small protein (140 aa) classically defined as intrinsically disordered $[92,93]$, later found in vivo as a tetramer enriched in $\alpha$-helices domains due to the presence to the $\mathrm{N}$-terminal $\alpha$-acetyl group [94]. For reasons not yet completely understood, this protein can undergo conformational switching towards parallel $\beta$ sheets enrichment that favors its aggregation first in oligomers and then in progressively longer fibrils, causing cellular distress, alteration of neuronal function and immune response activation [95]. Despite numerous studies on $\alpha \mathrm{S}$, its function is still debated. It has a cytoplasmic localization with enrichment in the axon terminals [96], where it plays a role in mediating the processes of fusion and invagination of the synaptic vesicles. In fact, besides the interaction with SNARE protein [96], $\alpha \mathrm{S}$ interacts with cellular lipids, mostly acidic ones [97, 98]. Studies using synthetic membranes have recently shown that $\alpha \mathrm{S}$ has a negligible affinity for the outer plasma membrane which increases considerably when enriched in gangliosides such as GM1 [99]. However, $\alpha \mathrm{S}$ has a great affinity for both the inner plasma membrane (IPM) and the membrane of the presynaptic vesicles (SVs), acting as a double anchor that binds the IPM with one arm and the SV with the other one, thus docking the SV to the membrane. The portion by which the $\alpha \mathrm{S}$ binds to the IPM also tends to bind the SVs each other, thus acting as a glue for the clustering of SVs in the presynaptic terminal. This is possible because $\alpha \mathrm{S}$ is a protein whose conformational dynamism is strictly dependent on the presence and composition of the lipids of the membranous structures to which it is associated. With similar biophysical techniques on synthetic membranes enriched with gangliosides, it was found that GM1 strongly interacts with $\alpha \mathrm{S}[100$, 101]. Furthermore, GM1 stabilizes the non-amyloidogenic $\alpha$-helix conformation of the protein, reason why GM1 was thought as a neuroprotective molecule, precisely in preventing pathological fibrillation of the $\alpha \mathrm{S}$. This aspect was further investigated in vivo where a functional correlation between GM1 and $\alpha \mathrm{S}$ was identified: a reduction of GM1 in the membrane of dopaminergic neurons increases the risk of $\alpha \mathrm{S}$ and Lewy body aggregates. Surprisingly, replacement therapy with LIGA20 (the permeable analogue of GM1) reduces these aggregates, highlighting a strong relationship between the levels of GM1 and $\alpha \mathrm{S}$ accumulation $[59,60]$. Specifically, the GM1 dis-aggregative properties seems to be attributable to its oligosaccharide chain: the administration of GM1 oligosaccharide in vivo led to a significant reduction of $\alpha S$ accumulation [47]. Further, the GM1 injection in rats overexpressing human mutant $\alpha \mathrm{S}$ (A53T) in $\mathrm{SN}$ was found to reduce $\alpha \mathrm{S}$ aggregation in striatum, displaying neurorestorative effects on nigro-striatal system [40].

A question inevitably arises from the following evaluations. It is established that the primary localization of GM1 and $\alpha \mathrm{S}$ is the same, that is at the level of axon terminals membranes, however the two "operate" in diametrically opposite regions: $\alpha \mathrm{S}$ works on the cytoplasmic side of the plasma membrane by mediating SVs docking and clustering, while GM1 is located on the outer layer of the membrane. How then is an interaction between the two physiologically made possible? It is known, as previously mentioned, that a small amount of GM1 is also present in the cytoplasm complexed with proteins. It is therefore speculated that this small amount of cytosolic GM1 could be responsible for the stabilizing effects of the $\alpha \mathrm{S}$ folding. There are very few studies on cytoplasmic GM1 and associated proteins. Only in one study, by photolabeling and crosslinking techniques, the authors isolated the proteins to which cytoplasmic GM1 was bound in human fibroblasts, identifying a pool of few but specific protein bands with molecular mass ranging from $30 \mathrm{kDa}$ to about $100 \mathrm{kDa}$ [12]. Monomeric $\alpha \mathrm{S}$ weights about $14 \mathrm{kDa}$ and appears to be excluded from the range, however fibroblasts express very low levels of $\alpha \mathrm{S}$ under physiological conditions. Thus, further studies aimed at demonstrating the putative relationship between cytoplasmic GM1 and $\alpha \mathrm{S}$ are still required as well as information about the role that plasma membrane GM1 could play in the physiopathology of $\alpha \mathrm{S}$. Indeed, $\alpha \mathrm{S}$ is released into the synaptic extracellular space upon neuronal activity [102], yet the dynamic of the process has not been clarified. During this process the rigid lipid raft domains where GM1 is enriched could be capable to block $\alpha \mathrm{S}$ spreading, a possible mechanism by which GM1 could avoid the protein aggregation [103]. To better understand this process it would be necessary to know how $\alpha \mathrm{S}$ linked to the external layer of the vesicles is capable to move, by diffusion or through specific channels, to the external layer of synaptic membrane following vesicle fusion [102]. Alternatively, we should consider that during membrane fusion, important membrane rearrangements could occur.

Lipid domains are rigid but very dynamic platform and any change in the content of their components requires a composition rearrangement [104]. We cannot exclude that a reduced synthesis of GM1 and GD1a makes the synaptic lipid raft no more suitable for interaction with $\alpha \mathrm{S}$. At this point, $\alpha \mathrm{S}$ would start with aggregation entering in such form into the post-synapsis and neural body, as well as in other brain cells.

Collectively, from the above, it clearly emerges the crucial role of GM1 ganglioside in maintaining the healthy 
status of nervous system. Although the precise mechanisms involved should be clarified, the GM1 capability to modulate the neurotrophins' signalings and to avoid $\alpha \mathrm{S}$ aggregation clearly highlights its role as regulator of neuronal homeostasis, capable of preventing the neurodegeneration. Thus, therapeutic strategies aimed at elevating GM1 levels are extremely attractive in PD context. However, only a low amount of peripherally administered GM1 can effectively reach the damaged neurons. The development of delivery strategies or the use of more permeable modified-GM1 can be useful. In this regard, the spotlight seems to be on the GM1 oligosaccharide, a brain-permeable small molecule maintaining all beneficial effects of the ganglioside from which it derives, thus demonstrating a strong therapeutic potential.

Author contribution SS participated in the conceptualization and first drafting of the article. MF wrote and edited paragraphs 2 and 3. EDB wrote and edited paragraphs 3.2 and 3.3. EC and GL prepared the figures and related legends. SS, MF, EDB, EC, GL and ML participated in the reading and editing and approved the final version of the article.

Funding Open access funding provided by Università degli Studi di Milano within the CRUI-CARE Agreement.

\section{Compliance with ethical standards}

Ethics approval This article does not contain any studies with human participants or animals performed by any of the authors.

Conflict of interest The authors declare that they have no conflicts of interest.

Open Access This article is licensed under a Creative Commons Attribution 4.0 International License, which permits use, sharing, adaptation, distribution and reproduction in any medium or format, as long as you give appropriate credit to the original author(s) and the source, provide a link to the Creative Commons licence, and indicate if changes were made. The images or other third party material in this article are included in the article's Creative Commons licence, unless indicated otherwise in a credit line to the material. If material is not included in the article's Creative Commons licence and your intended use is not permitted by statutory regulation or exceeds the permitted use, you will need to obtain permission directly from the copyright holder. To view a copy of this licence, visit http://creativecommons.org/licenses/by/4.0/.

\section{References}

1. Ledeen, R., Wu, G.: Gangliosides of the Nervous System. Methods Mol. Biol. 1804, 19-55 (2018)

2. Chiricozzi, E., Lunghi, G., Di Biase, E., Fazzari, M., Sonnino, S., Mauri, L.: GM1 Ganglioside Is A Key Factor in Maintaining the Mammalian Neuronal Functions Avoiding Neurodegeneration. Int. J. Mol. Sci. 21, (2020)

3. Aureli, M., Mauri, L., Ciampa, M.G., Prinetti, A., Toffano, G., Secchieri, C., Sonnino, S.: GM1 Ganglioside: Past Studies and Future Potential. Mol. Neurobiol. 53, 1824-1842 (2016)
4. Roseman, S.: The synthesis of complex carbohydrates by multiglycosyltransferase systems and their potential function in intercellular adhesion. Chem. Phys. Lipids. 5, 270-297 (1970)

5. Sonnino, S., Chigorno, V., Aureli, M., Masilamani, A.P., Valsecchi, M., Loberto, N., Prioni, S., Mauri, L., Prinetti, A.: Role of gangliosides and plasma membrane-associated sialidase in the process of cell membrane organization. Adv. Exp. Med. Biol. 705, 297-316 (2011)

6. Miyagi, T., Yamaguchi, K.: Mammalian sialidases: physiological and pathological roles in cellular functions. Glycobiology. 22, 880-896 (2012)

7. Tettamanti, G., Preti, A., Lombardo, A., Bonali, F., Zambotti, V.: Parallelism of subcellular location of major particulate neuraminidase and gangliosides in rabbit brain cortex. Biochim. Biophys. Acta. 306, 466-477 (1973)

8. Svennerholm, L.: The Gangliosides. J. Lipid Res. 5, 145-155 (1964)

9. Wiegandt, H.: The structure and the function of gangliosides. Angew. Chem. Int. Ed. Engl. 7, 87-96 (1968)

10. Hansson, H.A., Holmgren, J., Svennerholm, L.: Ultrastructural localization of cell membrane GM1 ganglioside by cholera toxin. Proc. Natl. Acad. Sci. USA. 74, 3782-3786 (1977)

11. Ledeen, R.W.: Ganglioside structures and distribution: are they localized at the nerve ending? J. Supramol. Struct. 8, 1-17 (1978)

12. Chigorno, V., Valsecchi, M., Acquotti, D., Sonnino, S., Tettamanti, G.: Formation of a cytosolic ganglioside-protein complex following administration of photoreactive ganglioside GM1 to human fibroblasts in culture. FEBS Lett. 263, 329-331 (1990)

13. Sonnino, S., Cantu, L., Corti, M., Acquotti, D., Venerando, B.: Aggregative properties of gangliosides in solution. Chem. Phys. Lipids. 71, 21-45 (1994)

14. Corti, M., Degiorgio, V., Ghidoni, R., Sonnino, S., Tettamanti, G.: Laser-light scattering investigation of the micellar properties of gangliosides. Chem. Phys. Lipids. 26, 225-238 (1980)

15. Ulrich-Bott, B., Wiegandt, H.: Micellar properties of glycosphingolipids in aqueous media. J. Lipid Res. 25, 1233-1245 (1984)

16. Sonnino, S., Prinetti, A., Mauri, L., Chigorno, V., Tettamanti, G.: Dynamic and structural properties of sphingolipids as driving forces for the formation of membrane domains. Chem. Rev. 106, 2111-2125 (2006)

17. Simons, K., Sampaio, J.L.: Membrane organization and lipid rafts. Cold Spring Harb. Perspect. Biol. 3, a004697 (2011)

18. Holmgren, J., Lonnroth, I., Svennerholm, L.: Tissue receptor for cholera exotoxin: postulated structure from studies with GM1 ganglioside and related glycolipids. Infect. Immun. 8, 208-214 (1973)

19. Kuziemko, G.M., Stroh, M., Stevens, R.C.: Cholera toxin binding affinity and specificity for gangliosides determined by surface plasmon resonance. Biochemistry. 35, 6375-6384 (1996)

20. Chiricozzi, E., Mauri, L., Ciampa, M.G., Prinetti, A., Sonnino, S.: On the use of cholera toxin. Glycoconj. J. 35, 161-163 (2018)

21. Ledeen, R.W., Wu, G.: The multi-tasked life of GM1 ganglioside, a true factotum of nature. Trends Biochem. Sci. 40, 407-418 (2015)

22. Horowitz, S.H.: Ganglioside (Cronassial) therapy in diabetic neuropathy. Adv. Exp. Med. Biol. 174, 593-600 (1984)

23. Siagoside, G.M.: Sygen. Drugs RD. 1, 36-7 (1999)

24. Hallett, M., Flood, T., Slater, N., Dambrosia, J.: Trial of ganglioside therapy for diabetic neuropathy. Muscle Nerve. 10, 822-825 (1987)

25. Bradley, W.G., Badger, G.J., Tandan, R., Fillyaw, M.J., Young, J., Fries, T.J., Krusinski, P.B., Witarsa, M., Boerman, J., Blair, C.J.: Double-blind controlled trials of Cronassial in chronic neuromuscular diseases and ataxia. Neurology. 38, 1731-1739 (1988)

26. Sobolewski, P.: Cronassial in the treatment of neuropathies and atrophy of the optic nerve. Klin. Oczna. 94, 57-58 (1992) 
27. Gottfries, C.G.: Therapy options in Alzheimer's disease. Br. J. Clin. Pract. 48, 327-330 (1994)

28. Augustinsson, L.E., Blennow, K., Blomstrand, C., Brane, G., Ekman, R., Fredman, P., Karlsson, I., Kihlgren, M., Lehmann, W., Lekman, A., Mansson, J.E., Ramstrom, I., Wallin, A., Wikkelso, C., Gottfries, C.G., Svennerholm, L.: Intracerebroventricular administration of GM1 ganglioside to presenile Alzheimer patients. Dement. Geriatr. Cogn. Disord. 8, 26-33 (1997)

29. Geisler, F.H., Coleman, W.P., Grieco, G., Poonian, D., Sygen Study, G.: The Sygen multicenter acute spinal cord injury study. Spine (Phila Pa 1976). 26, S87-98 (2001)

30. Geisler, F.H., Dorsey, F.C., Coleman, W.P.: Recovery of motor function after spinal-cord injury-a randomized, placebocontrolled trial with GM-1 ganglioside. N. Engl. J. Med. 324, 1829-1838 (1991)

31. Geisler, F.H., Dorsey, F.C., Coleman, W.P.: Correction: recovery of motor function after spinal-cord injury-a randomized, placebo-controlled trial with GM-1 ganglioside. N. Engl. J. Med. 325, 1659-1660 (1991)

32. Hadley, M.N., Walters, B.C., Grabb, P.A., Oyesiku, N.M., Przybylski, G.J., Resnick, D.K., Ryken, T.C., Mielke, D.H.: Guidelines for the management of acute cervical spine and spinal cord injuries. Clin. Neurosurg. 49, 407-498 (2002)

33. Walters, B.C., Hadley, M.N.: Guidelines for GM-1 ganglioside in acute spinal cord injury. Neurosurgery. 73, E752 (2013)

34. Hadjiconstantinou, M., Mariani, A.P., Neff, N.H.: GM1 ganglioside-induced recovery of nigrostriatal dopaminergic neurons after MPTP: an immunohistochemical study. Brain Res. 484, 297-303 (1989)

35. De Girolamo, L.A., Hargreaves, A.J., Billett, E.E.: Protection from MPTP-induced neurotoxicity in differentiating mouse N2a neuroblastoma cells. J. Neurochem. 76, 650-660 (2001)

36. Nicotra, A., Parvez, S.: Apoptotic molecules and MPTP-induced cell death. Neurotoxicol. Teratol. 24, 599-605 (2002)

37. Meredith, G.E., Rademacher, D.J.: MPTP mouse models of Parkinson's disease: an update. J. Parkinsons Dis. 1, 19-33 (2011)

38. Toffano, G., Savoini, G., Moroni, F., Lombardi, G., Calza, L., Agnati, L.F.: GM1 ganglioside stimulates the regeneration of dopaminergic neurons in the central nervous system. Brain Res. 261, 163-166 (1983)

39. Agnati, L.F., Fuxe, K., Calza, L., Goldstein, M., Toffano, G., Giardino, L., Zoli, M.: Further studies on the effects of the GM1 ganglioside on the degenerative and regenerative features of mesostriatal dopamine neurons. Acta Physiol. Scand. Suppl. 532, 37-44 (1984)

40. Schneider, J.S., Aras, R., Williams, C.K., Koprich, J.B., Brotchie, J.M., Singh, V.: GM1 Ganglioside Modifies alpha-Synuclein Toxicity and is Neuroprotective in a Rat alpha-Synuclein Model of Parkinson's Disease. Sci. Rep. 9, 8362 (2019)

41. Schneider, J.S., Sendek, S., Daskalakis, C., Cambi, F.: GM1 ganglioside in Parkinson's disease: Results of a five year open study. J. Neurol. Sci. 292, 45-51 (2010)

42. Schneider, J.S., Gollomp, S.M., Sendek, S., Colcher, A., Cambi, F., Du, W.: A randomized, controlled, delayed start trial of GM1 ganglioside in treated Parkinson's disease patients. J. Neurol. Sci. 324, 140-148 (2013)

43. Schneider, J.S., Cambi, F., Gollomp, S.M., Kuwabara, H., Brasic, J.R., Leiby, B., Sendek, S., Wong, D.F.: GM1 ganglioside in Parkinson's disease: Pilot study of effects on dopamine transporter binding. J. Neurol. Sci. 356, 118-123 (2015)

44. Chiricozzi, E., Pome, D.Y., Maggioni, M., Di Biase, E., Parravicini, C., Palazzolo, L., Loberto, N., Eberini, I., Sonnino, S.: Role of the GM1 ganglioside oligosaccharide portion in the TrkA-dependent neurite sprouting in neuroblastoma cells. J. Neurochem. 143, 645659 (2017)
45. Chiricozzi, E., Biase, E.D., Maggioni, M., Lunghi, G., Fazzari, M., Pome, D.Y., Casellato, R., Loberto, N., Mauri, L., Sonnino, S.: GM1 promotes TrkA-mediated neuroblastoma cell differentiation by occupying a plasma membrane domain different from TrkA. J. Neurochem. 149, 231-241 (2019)

46. Chiricozzi, E., Maggioni, M., di Biase, E., Lunghi, G., Fazzari, M., Loberto, N., Elisa, M., Scalvini, F.G., Tedeschi, G., Sonnino, S.: The Neuroprotective Role of the GM1 Oligosaccharide, II(3) Neu5Ac-Gg4. Neuroblastoma Cells Mol. Neurobiol. 56, 66736702 (2019)

47. Chiricozzi, E., Mauri, L., Lunghi, G., Di Biase, E., Fazzari, M., Maggioni, M., Valsecchi, M., Prioni, S., Loberto, N., Pome, D.Y., Ciampa, M.G., Fato, P., Verlengia, G., Cattaneo, S., Assini, R., Wu, G., Alselehdar, S., Ledeen, R.W., Sonnino, S.: Parkinson's disease recovery by GM1 oligosaccharide treatment in the B4galnt1(+/-) mouse model. Sci. Rep. 9, 19330 (2019)

48. Fazzari, M., Audano, M., Lunghi, G., Di Biase, E., Loberto, N., Mauri, L., Mitro, N., Sonnino, S., Chiricozzi, E.: The oligosaccharide portion of ganglioside GM1 regulates mitochondrial function in neuroblastoma cells. Glycoconj. J. 37, 293-306 (2020)

49. Di Biase, E., Lunghi, G., Fazzari, M., Maggioni, M., Pome, D.Y., Valsecchi, M., Samarani, M., Fato, P., Ciampa, M.G., Prioni, S., Mauri, L., Sonnino, S., Chiricozzi, E.: Gangliosides in the differentiation process of primary neurons: the specific role of GM1-oligosaccharide. Glycoconj. J. 37, 329-343 (2020)

50. Di Biase, E., Lunghi, G., Maggioni, M., Fazzari, M., Pome, D.Y., Loberto, N., Ciampa, M.G., Fato, P., Mauri, L., Sevin, E., Gosselet, F., Sonnino, S., Chiricozzi, E.: GM1 Oligosaccharide Crosses the Human Blood-Brain Barrier In Vitro by a Paracellular Route. Int. J. Mol. Sci. 21 (2020)

51. Lunghi, G., Fazzari, M., Di Biase, E., Mauri, L., Sonnino, S., Chiricozzi, E.: Modulation of calcium signaling depends on the oligosaccharide of GM1 in Neuro2a mouse neuroblastoma cells. Glycoconj. J. (2020)

52. Svennerholm, L., Bostrom, K., Jungbjer, B., Olsson, L.: Membrane lipids of adult human brain: lipid composition of frontal and temporal lobe in subjects of age 20 to 100 years. J. Neurochem. 63, 1802-1811 (1994)

53. Ledeen, R.W., Wu, G.: Gangliosides, alpha-Synuclein, and Parkinson's Disease. Prog. Mol. Biol. Transl. Sci. 156, 435454 (2018)

54. Schneider, J.S.: Altered expression of genes involved in ganglioside biosynthesis in substantia nigra neurons in Parkinson's disease. PLoS One. 13, e0199189 (2018)

55. Seyfried, T.N., Choi, H., Chevalier, A., Hogan, D., Akgoc, Z., Schneider, J.S.: Sex-Related Abnormalities in Substantia Nigra Lipids in Parkinson's Disease. ASN Neuro. 10, 1759091418781889 (2018)

56. Hadaczek, P., Wu, G., Sharma, N., Ciesielska, A., Bankiewicz, K., Davidow, A.L., Lu, Z.H., Forsayeth, J., Ledeen, R.W.: GDNF signaling implemented by GM1 ganglioside; failure in Parkinson's disease and GM1-deficient murine model. Exp. Neurol. 263, 177-189 (2015)

57. Wu, G., Lu, Z.H., Kulkarni, N., Amin, R., Ledeen, R.W.: Mice lacking major brain gangliosides develop parkinsonism. Neurochem. Res. 36, 1706-1714 (2011)

58. Forsayeth, J., Hadaczek, P.: Ganglioside Metabolism and Parkinson's Disease. Front. Neurosci. 12, 45 (2018)

59. Wu, G., Lu, Z.H., Kulkarni, N., Ledeen, R.W.: Deficiency of ganglioside GM1 correlates with Parkinson's disease in mice and humans. J. Neurosci. Res. 90, 1997-2008 (2012)

60. Wu, G., Lu, Z.H., Seo, J.H., Alselehdar, S.K., DeFrees, S., Ledeen, R.W.: Mice deficient in GM1 manifest both motor and non-motor 
symptoms of Parkinson's disease; successful treatment with synthetic GM1 ganglioside. Exp. Neurol. 329, 113284 (2020)

61. Yoon, S.J., Nakayama, K., Hikita, T., Handa, K., Hakomori, S.I.: Epidermal growth factor receptor tyrosine kinase is modulated by GM3 interaction with N-linked GlcNAc termini of the receptor. Proc. Natl. Acad. Sci. USA. 103, 18987-18991 (2006)

62. Mutoh, T., Tokuda, A., Miyadai, T., Hamaguchi, M., Fujiki, N.: Ganglioside GM1 binds to the Trk protein and regulates receptor function. Proc. Natl. Acad. Sci USA. 92, 5087-5091 (1995)

63. Kreutter, D., Kim, J.Y., Goldenring, J.R., Rasmussen, H., Ukomadu, C., DeLorenzo, R.J., Yu, R.K.: Regulation of protein kinase $\mathrm{C}$ activity by gangliosides. J. Biol. Chem. 262, 1633-1637 (1987)

64. Bassi, R., Chigorno, V., Fiorilli, A., Sonnino, S., Tettamanti, G.: Exogenous gangliosides GD1b and GD1b-lactone, stably associated to rat brain P2 subcellular fraction, modulate differently the process of protein phosphorylation. J. Neurochem. 57, 1207-1211 (1991)

65. Pellizzari, R., Rossetto, O., Schiavo, G., Montecucco, C.: Tetanus and botulinum neurotoxins: mechanism of action and therapeutic uses. Philos. Trans. R Soc. Lond. B. Biol. Sci. 354, 259-268 (1999)

66. Tsuji, S., Yamashita, T., Matsuda, Y., Nagai, Y.: A novel glycosignaling system: GQ1b-dependent neuritogenesis of human neuroblastoma cell line, GOTO, is closely associated with GQ1b-dependent ecto-type protein phosphorylation. Neurochem. Int. 21, 549-554 (1992)

67. Zancada, L., Sanchez-Juanes, F., Alonso, J.M., Hueso, P.: Neutral glycosphingolipid content of ovine milk. J. Dairy Sci. 93, 19-26 (2010)

68. Aerts, J., Artola, M., van Eijk, M., Ferraz, M.J., Boot, R.G.: Glycosphingolipids and Infection. Potential New Therapeutic Avenues. Front Cell Dev. Biol. 7, 324 (2019)

69. Tomasi, M., Roda, L.G., Ausiello, C., D’Agnolo, G., Venerando, B., Ghidoni, R., Sonnino, S., Tettamanti, G.: Interaction of GMI ganglioside with bovine serum albumin: formation and isolation of multiple complexes. Eur. J. Biochem. 111, 315-324 (1980)

70. Venerando, B., Roberti, S., Sonnino, S., Fiorilli, A., Tettamanti, G.: Interactions of ganglioside GM1 with human and fetal calf sera. Formation of ganglioside-serum albumin complexes. Biochim. Biophys. Acta. 692, 18-26 (1982)

71. Ferrari, G., Anderson, B.L., Stephens, R.M., Kaplan, D.R., Greene, L.A.: Prevention of apoptotic neuronal death by GM1 ganglioside. Involvement of Trk neurotrophin receptors. J. Biol. Chem. 270, 3074-80 (1995)

72. Farooqui, T., Franklin, T., Pearl, D.K., Yates, A.J.: Ganglioside GM1 enhances induction by nerve growth factor of a putative dimer of TrkA. J. Neurochem. 68, 2348-2355 (1997)

73. Schwarzmann, G., Hoffmann-Bleihauer, P., Schubert, J., Sandhoff, K., Marsh, D.: Incorporation of ganglioside analogues into fibroblast cell membranes. A spin-label study. Biochemistry. 22, 5041-5048 (1983)

74. Chigorno, V., Pitto, M., Cardace, G., Acquotti, D., Kirschner, G., Sonnino, S., Ghidoni, R., Tettamanti, G.: Association of ganglio-sides to fibroblasts in culture: a study performed with GM1 [14C]-labelled at the sialic acid acetyl group. Glycoconj. J. 2, 279-291 (1985)

75. Riboni, L., Prinetti, A., Pitto, M., Tettamanti, G.: Patterns of endogenous gangliosides and metabolic processing of exogenous gangliosides in cerebellar granule cells during differentiation in culture. Neurochem. Res. 15, 1175-1183 (1990)

76. Ghidoni, R., Fiorilli, A., Trinchera, M., Venerando, B., Chigorno, V., Tettamanti, G.: Uptake, cell penetration and metabolic processing of exogenously administered GM1 ganglioside in rat brain. Neurochem. Int. 15, 455-465 (1989)
77. Mutoh, T., Hamano, T., Yano, S., Koga, H., Yamamoto, H., Furukawa, K., Ledeen, R.W.: Stable transfection of GM1 synthase gene into GM1-deficient NG108-15 cells, CR-72 cells, rescues the responsiveness of Trk-neurotrophin receptor to its ligand. NGF. Neurochem. Res. 27, 801-806 (2002)

78. Da Silva, J.S., Hasegawa, T., Miyagi, T., Dotti, C.G., AbadRodriguez, J.: Asymmetric membrane ganglioside sialidase activity specifies axonal fate. Nat. Neurosci. 8, 606-615 (2005)

79. Aureli, M., Loberto, N., Lanteri, P., Chigorno, V., Prinetti, A., Sonnino, S.: Cell surface sphingolipid glycohydrolases in neuronal differentiation and aging in culture. J. Neurochem. 116, 891-899 (2011)

80. Di Biase, E.: GM1 oligosaccharide accounts for GM1 role in enhancing neuronal development acting on TrkA-MAPK pathway. PhD Thesis, University of Milan Archive.(2019). http://hdl. handle.net/2434/692335.

81. Ichikawa, N., Iwabuchi, K., Kurihara, H., Ishii, K., Kobayashi, T., Sasaki, T., Hattori, N., Mizuno, Y., Hozumi, K., Yamada, Y., Arikawa-Hirasawa, E.: Binding of laminin-1 to monosialoganglioside GM1 in lipid rafts is crucial for neurite outgrowth. J. Cell Sci. 122, 289-299 (2009)

82. Waugh, M.G.: Raft-like membranes from the trans-Golgi network and endosomal compartments. Nat. Protoc. 8, 2429-2439 (2013)

83. Kawai, K., Takahashi, M.: Intracellular RET signaling pathways activated by GDNF. Cell Tissue Res. 382, 113-123 (2020)

84. Eigenbrot, C., Gerber, N.: X-ray structure of glial cell-derived neurotrophic factor at 1.9 A resolution and implications for receptor binding. Nat. Struct. Biol. 4, 435-8 (1997)

85. Conway, J.A., Ince, S., Black, S., Kramer, E.R.: GDNF/RET signaling in dopamine neurons in vivo. Cell Tissue Res. 382, $135-146$ (2020)

86. Jing, S., Wen, D., Yu, Y., Holst, P.L., Luo, Y., Fang, M., Tamir, R., Antonio, L., Hu, Z., Cupples, R., Louis, J.C., Hu, S., Altrock, B.W., Fox, G.M.: GDNF-induced activation of the ret protein tyrosine kinase is mediated by GDNFR-alpha, a novel receptor for GDNF. Cell 85, 1113-1124 (1996)

87. Li, J., Shang, G., Chen, Y.J., Brautigam, C.A., Liou, J., Zhang, X., Bai, X.C.: Cryo-EM analyses reveal the common mechanism and diversification in the activation of RET by different ligands. Elife. 8, (2019)

88. Tansey, M.G., Baloh, R.H., Milbrandt, J., Johnson, E.M. Jr.: GFRalpha-mediated localization of RET to lipid rafts is required for effective downstream signaling, differentiation, and neuronal survival. Neuron. 25, 611-623 (2000)

89. Newburn, E.N., Duchemin, A.M., Neff, N.H., Hadjiconstantinou, M.: GM1 ganglioside enhances Ret signaling in striatum. J. Neurochem. 130, 541-554 (2014)

90. Kramer, E.R., Liss, B.: GDNF-Ret signaling in midbrain dopaminergic neurons and its implication for Parkinson disease. FEBS Lett. 589, 3760-3772 (2015)

91. Bernal-Conde, L.D., Ramos-Acevedo, R., Reyes-Hernandez, M.A., Balbuena-Olvera, A.J., Morales-Moreno, I.D., ArgueroSanchez, R., Schule, B., Guerra-Crespo, M.: Alpha-Synuclein Physiology and Pathology: A Perspective on Cellular Structures and Organelles. Front. Neurosci. 13, 1399 (2019)

92. Fauvet, B., Mbefo, M.K., Fares, M.B., Desobry, C., Michael, S., Ardah, M.T., Tsika, E., Coune, P., Prudent, M., Lion, N., Eliezer, D., Moore, D.J., Schneider, B., Aebischer, P., El-Agnaf, O.M., Masliah, E., Lashuel, H.A.: alpha-Synuclein in central nervous system and from erythrocytes, mammalian cells, and Escherichia coli exists predominantly as disordered monomer. J. Biol. Chem. 287, 15345-15364 (2012)

93. Burre, J., Vivona, S., Diao, J., Sharma, M., Brunger, A.T., Sudhof, T.C.: Properties of native brain alpha-synuclein. Nature. 498, E4-6; discussion E6-7 (2013) 
94. Bartels, T., Choi, J.G., Selkoe, D.J.: alpha-Synuclein occurs physiologically as a helically folded tetramer that resists aggregation. Nature. 477, 107-110 (2011)

95. Ingelsson, M.: Alpha-Synuclein Oligomers-Neurotoxic Molecules in Parkinson's Disease and Other Lewy Body Disorders. Front. Neurosci. 10, 408 (2016)

96. Bendor, J.T., Logan, T.P., Edwards, R.H.: The function of alphasynuclein. Neuron. 79, 1044-1066 (2013)

97. Davidson, W.S., Jonas, A., Clayton, D.F., George, J.M.: Stabilization of alpha-synuclein secondary structure upon binding to synthetic membranes. J. Biol. Chem. 273, 9443-9449 (1998)

98. Zhu, M., Fink, A.L.: Lipid binding inhibits alpha-synuclein fibril formation. J. Biol. Chem. 278, 16873-16877 (2003)

99. Man, W.K., Tahirbegi, B., Vrettas, M.D., Preet, S., Ying, L., Vendruscolo, M., De Simone, A., Fusco, G.: The docking of synaptic vesicles on the presynaptic membrane induced by alphasynuclein is modulated by lipid composition. Nat. Commun. 12, $927(2021)$

100. Martinez, Z., Zhu, M., Han, S., Fink, A.L.: GM1 specifically interacts with alpha-synuclein and inhibits fibrillation. Biochemistry. 46, 1868-1877 (2007)

101. Bartels, T., Kim, N.C., Luth, E.S., Selkoe, D.J.: N-alpha-acetylation of alpha-synuclein increases its helical folding propensity, GM1 binding specificity and resistance to aggregation. PLoS One. 9, e103727 (2014)

102. Fortin, D.L., Nemani, V.M., Voglmaier, S.M., Anthony, M.D., Ryan, T.A., Edwards, R.H.: Neural activity controls the synaptic accumulation of alpha-synuclein. J. Neurosci. 25, 10913-10921 (2005)

103. Fortin, D.L., Troyer, M.D., Nakamura, K., Kubo, S., Anthony, M.D., Edwards, R.H.: Lipid rafts mediate the synaptic localization of alpha-synuclein. J. Neurosci. 24, 6715-6723 (2004)

104. Ottico, E., Prinetti, A., Prioni, S., Giannotta, C., Basso, L., Chigorno, V., Sonnino, S.: Dynamics of membrane lipid domains in neuronal cells differentiated in culture. J. Lipid Res. 44, 2142-2151 (2003)

105. Chiricozzi, E., Di Biase, E., Lunghi, G., Fazzari, M., Loberto, N., Aureli, M., Mauri, L., Sonnino, S.: Turning the spotlight on the oligosaccharide chain of GM1 ganglioside. Glycoconj. J. 38, 101-117 (2021)

Publisher's Note Springer Nature remains neutral with regard to jurisdictional claims in published maps and institutional affiliations. 